\title{
Reference:
}

Ullán, A. M., Belver, M. H., Badía, M., Moreno, C., Garrido, E., Gómez-Isla, J., . . . Tejedor, L. (2013). Contributions of an artistic educational program for older people with early dementia: An exploratory qualitative study. Dementia, 12(4), 425-446. doi: $10.1177 / 1471301211430650$

The definitive version is available at

http://dem.sagepub.com/content/12/4/425 
Contributions of an Artistic Educational Program for Older People with Early Dementia: An Exploratory Qualitative Study

Ana M. Ullán (1); Manuel H. Belver (2); Carmen Moreno (2); Eugenio Garrido (1); José Gómez-Isla (3); Elena Gonzalez-Ingelmo (4); Juan Delgado (5); Isabel Serrano (5);

Marta Badía (5); Carmen Herrero (1); Paloma Manzanera (1); Laura Tejedor (3)

(1) Department of Social Psychology, University of Salamanca, Salamanca, Spain

(2) Department of Art Education, Complutense University, Madrid, Spain

(3) Department of Art, University of Salamanca, Salamanca, Spain

(4) CRE Alzheimer, Salamanca, Spain

(5) Department of Psychology, University of Salamanca, Salamanca, Spain

The corresponding address is:

Ana M Ullán, Facultad de Ciencias Sociales, Campus Miguel de Unamuno. 37007, Salamanca, Spain. Phone: +34-923-294400. E-mail: ullan@usal.es 


\title{
Contributions of an Artistic Educational Program for Older People with Early Dementia: An Exploratory Qualitative Study
}

\begin{abstract}
Objective: To describe a contemporary artistic educational program based on photographic cyanotype techniques and to present the results of the program carried out with older people with early dementia. We determined whether these people could participate in the program, their viewpoint about it, and what this program could contribute to their experience.
\end{abstract}

Method: 21 people diagnosed with mild or moderate dementia participated in a series of artistic education workshops. While conducting the workshops, participant observation was carried out, and the participants' engagement was assessed. Upon completing the series, five focus groups were carried out with the participants with dementia, and another focus group with their professional caretakers.

Results: we observed the participants' high level of commitment to the activity and their interest in learning new things. We also observed the participants' satisfaction during the creative process and with their results. The artistic activities not only reinforced the feelings of capacity of the participants with early dementia but also transmitted a positive image of them.

Conclusions: Dementia was not an obstacle to participate in the program, which was an opportunity for creativity, learning, enjoyment, and communication of people with dementia. In the authors' opinion, facilitating access to art and artistic education to people with early dementia can contribute to enforcing their rights and to improving the care system.

Keywords: early dementia; creativity; artistic education; art; psychosocial intervention 


\section{Contributions of an Artistic Educational Program for Older People with Early Dementia: An Exploratory Qualitative Study}

Article 27 of the Universal Declaration of Human Rights acknowledges that every person has the right to take part freely in the cultural life of the community and to enjoy the arts. However, in practice, dementia can imply a considerable reduction of the opportunities to make effective use of this right because it has been shown to be a factor that is negatively related to people's participation in cultural and artistic activities. (Paillard-Borg, Wang, Winblad, \& Fratiglioni, 2009). And this occurs despite the fact that diverse studies have revealed a positive relation between participation in this kind of activities and health and well-being throughout the ageing processes (Cohen, 2009; Cohen et al., 2006; Fisher \& Specht, 1999; Wikström, 2002).

Limiting the cultural opportunities of people with early dementia is unjustified, because this pathology does not imply any obstacle to art-related behaviors. Besides the therapeutic settings of art therapy or occupational therapy, there are few investigations about art-related activities in people with dementia who have no artistic trajectory prior to their disease. However, the few documented experiences agree that dementia itself is not an obstacle for cultural artistic consumption such as visits to art galleries or museums (MacPherson, Bird, Anderson, Davis, \& Blair, 2009; Ziesel, 2009). Likewise, there are documented cases of artists affected by dementia whose skills were preserved for a long time during their illness, even after other cognitive functions presented severe deficits (Cummings, Miller, Christensen, \& Cherry, 2008; Fornazzari, 2005). There are also documented cases of people with neurodegenerative diseases who have developed artistic interests and skills they did not have prior to their illness (Miller, Boone, 
Cummings, Read, \& Mishkin, 2000; Miller et al., 1998). In principle, this observation seemed like a casual coincidence, but experience has proved that it is a relatively frequent theme in patients with fronto-temporal dementia, and a large number of patients with semantic dementias develop considerable visual creativity (Cummings et al., 2008).

Art is a specifically human activity, mainly associated with abstract and symbolic cognition but—in contrast to language — the skills and artistic creativity are linked to broad, diverse, and redundant brain areas (Zaidel, 2010), which could explain the persistence of their functionality, even in the case of people with brain injury or dementia.

And if complex artistic creativity seems remarkably resistant to brain ailments, the behaviors of aesthetic appreciation seem to be preserved in the case of people with Alzheimer's disease, at least in the early stages of the illness. Halpern et al. (Halpern, Ly, Elkin-Frankston, \& O'Connor, 2008) observed that the aesthetic preferences of people with Alzheimer's disease were as stable as those of people from the control group who did not suffer from this illness, even in the case of total amnesia for pictures seen two weeks previously.

However, changes in the way they paint have also been verified in people after they develop neurodegenerative diseases. But the analysis and meaning of these changes, both from the neurological viewpoint and from the creative, aesthetic, and artistic viewpoint is complex (Lopez-Pousa, 2009). Alzheimer's disease can produce a loss of the capacity to perform realistic copies, but it does not seem to have the same 
effect on composition or the use of color (Cummings et al., 2008). A similar process can be observed in other dementias (Drago et al., 2006; Mell, Howard, \& Miller, 2003). Alzheimer patients, compared to same-aged people without this pathology, may prefer simpler plastic compositions, with fewer elements or less symmetry (Seifert, Drennan, \& Baker, 2001), but, the simplicity of plastic elements in itself does not lead to less creativity or artistic value. In art, there is no kind of basic elements-like words for language - that justifies a simple unidimensional evaluation of the artistic value of a plastic composition. On the contrary, artistic, aesthetic, or creative value involves many factors, some related to the work itself (balance, color, composition, etc.), and others related to the connection of the work to artistic trajectories or movements, and still others related to the meaning of the work in the personal and social context, both of the creator and of the beholder (Ullán, 1995). These aspects must be taken into account to appraise the extent to which early dementia itself does not justify the limitation of artistic activities, either the production or aesthetic appreciation.

The concurrent consideration of the limited cultural opportunities of people with dementia on the one hand, and, on the other, the hypothesis that dementia itself should not be an obstacle for such participation led us to propose and develop an artistic educational program for people with early dementia. The goal of this work is to present the results of this program. This is an exploratory qualitative study designed to determine whether people with early dementia could participate in a contemporary artistic educational program based on photographic cyanotype techniques, to establish their viewpoint of the program, and to discover what such a program could contribute to these people's experience. 


\section{Method}

All the users of the State Day Center for People with Alzheimer's Disease and Other Dementias of Salamanca (Spain) were considered eligible to participate in the program. The study was approved by the Ethics Committee of the Salamanca (Spain) Center of State Reference of Care for People with Alzheimer's Disease and other Dementias. All the people who participated gave their consent and could drop out at any time. Moreover, consent was requested of each participant at the beginning of each session, and they could refuse to participate if they so wished.

\section{Description of the program}

Table 2 presents the basic points used to design the program. The program was organized in a series of workshops, each one of which was carried out in two stages. The first stage consisted of the presentation of audiovisual material of diverse artists' works of art, which had been prepared for the participants to view and comment on. After the program had started, the audiovisual material presented to the participants in the first phase of the workshops
Table 2.

General criteria for the design of the program of artistic activities

1. The artistic activities must be designed so they can be included in an artistic educational program for adults without any neurological pathologies.

2. The activities designed will promote contact with works of art and relevant artists of diverse epochs and styles.

3. The artistic techniques used will promote the participants' creativity and development of a personal work.

4. The aim is to establish connections between the works of art included in the program and the participants' personal creations, either through the technique, through the content, or through the formal and/or conceptual aspects of the creations.

5. Care should be taken with the design of the artistic activities so they promote the participants' sense of personal value and identity.

6. The artistic activities designed should favor the use of the participants' cognitive capacities (such as relation, discrimination, association, etc.) and of communication capacities. 
incorporated photographs of the participants' works and of the processes followed to produce them. The painting used to initiate the program was "Las meninas" by Diego Velázquez. We used the on-line gallery of the Museo del Prado (http://www.museodelprado.es/coleccion/galeria-on-line/) so the participants could see the painting, both in the complete format and various interesting details of the painting. We chose this painting to start the program for various reasons: because it is a wellknown painting, valued by the general public, but also because of the relevance of this painting in the history of art: it is a painters' painting, in which the artist appears in the scene of the painting and several characters seem to be looking at the beholder. Moreover, we thought that this painting could introduce Table 3. Description of the photographic cyanotype procedure the participants to other The process of cyanotype uses two chemical compositions: an $8 \%$ solution of ferry cyanide of potassium and a $20 \%$ solution of ferric ammonium citrate. The final mixture used ( $50 \%$ of each component) is a photosensitive aqueous solution used to ways of representation coat a material, usually paper, although a workshop using the mixture on stones was also carried out. Once the photosensitive solution has been applied to the supporting surface (paper, stone, etc.), it is allowed to dry. Upon exposing the emulsioned surface to sunlight, the iron in the exposed areas is reduced, changing to a blue tone, which lends its name to the procedure. Impressions can be made on any object or with large through the interpretations format negative. After exposure, the copy is rinsed in water to eliminate the salts that were not reduced. When rinsing the copy, the image begins to "appear" with the characteristic Prussian blue color. The process can be done faster by immersing the painters like Picasso, the impression in a $3 \%$ solution of hydrogen peroxide.

Equipo Crónica [The

Chronic Team], etc.

The second stage consisted of the participants' performing a personal work with cyanotype. Cyanotype is a monochrome photographic procedure by which a blue copy of a picture is obtained (see Table 3 for a brief description of the procedure). It is simple to apply, UVA rays are the luminous source to obtain the positives, and no dark room is needed for its manipulation, the developer used is water, and no fixer is needed. The complete developing process is relatively short and can be combined with other techniques like drawing, painting, etc. We chose this photographic technique because of 
the aesthetic quality of its results, its simplicity, and the appeal of the developing process, and because one can pause during the composition - almost tridimensionalwithout fine mobility impairments affecting the results, the participants do not have to outline the objects to be represented, and it allows a very personal elaboration of the graphic work. Five workshops were designed and carried out. Table 4 shows the artists and works included in the first phase of each workshop. The design of the workshops was sequential, each one was designed taking into account the general criteria described in detail in Table 2 and the participants' engagement and their response to the prior activities.

The workshops were carried out in one or two sessions with a variable duration between 60 and 90 minutes. The sessions were directed by two artistic educators who presented the audiovisual material to the participants, explained the procedures to be followed, and supported the participants during the creative process.

\section{Data collection}

Four techniques were used for data collection: a) participant observation, b) assessment by the educators, c) focus group with people with dementia as participants, d) focus group with professional caretakers.

From the beginning of the sessions, we decided that it was appropriate to carry out participant observation during the sessions. Two of the authors (AMU and MHB), with experience in psychology and art, respectively, joined the group of participants and educators and performed this participant observation. They kept a written field record 
and a photographic record of the sessions that allowed them to document the processes graphically and to make an image diary of the sessions.

At the end of each session, the artistic educators who had directed it filled in a summary form about each participant, according to the format shown in Table 5. In addition, they briefly described the attitudes and reactions they had observed of each participant and made some considerations about the group that had participated in the session. The forms were completed by agreement between the two educators. Their level of disagreement was very low and in case of doubt, the most noncommittal response option was chosen (option $d$ for Question 4, option $b$ for Question 5; and option $c$ for Question 6).

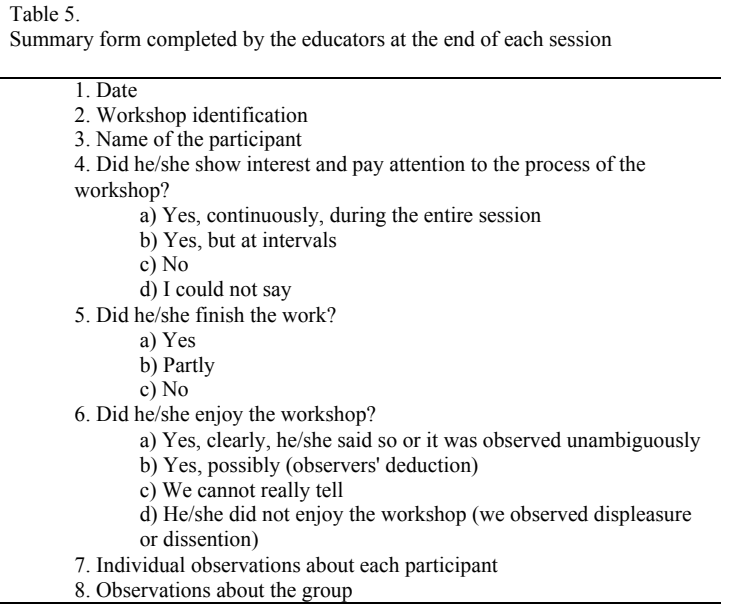

Upon completing the cycle of the five workshops mentioned in this work, five focus groups were conducted with the people with dementia who had participated in this experience. In each group, participants were three people with dementia, the two educators who directed the group, and one of the investigators who had performed the participant observation (AMU), who videotaped these focus groups. Due to health or to organizational problems, six people could not participate in the focus groups. These focus groups were presented as an opportunity to review the works made in the workshops and to express one's opinions of them and of the experience. The participants received the works they had made during the four months of the program, and depending on their preferences, they chose one or two works to frame with a passe 
partout and glass in that same session. Once framed and commented on, the authors were encouraged to give them a title. The processes of selecting, framing, and finding a title for the works were considered a good opportunity to promote participants' interventions and thus determine their perspective of the experience. The video recordings of these focus groups with the participants were reviewed independently by two investigators. One of them (AMU) had been present during the focus groups, in charge of the video, and the other one (MHB) knew the participants but had not been present during the focus groups. After reviewing the video recordings, in order to systematize the information that could be extracted, each observer independently filled in the checkboxes of the guideline included in Table 6 and wrote down the participants' especially significant contributions.

After completing the five above-

Table 6.

Guideline for the analysis of the video recordings of the focus groups with the participants

The participants paid attention to their works (they look at them with concentration)

mentioned workshops, another focus The participants express opinions and attitudes about their own works (pleasure or criticism)

The participants express opinions and attitudes about others' works group with the socio-health care professionals who cared for the The participants pay attention to the opinions expressed by others

The climate is relaxed with episodes of humor (laughter)

They carry out the tasks of giving a personal title to the works (descriptive, participants at the day center was humorous, and often poetic)

conducted. By means of this focus group, The exchange of questions and answers among the monitors and participants is appropriate

The participants make suggestions or proposals for the program we wished to determine these Significant contributions ("verbatim") by the participants

professionals' perspective of the program activities and of the participants' reactions to the program, especially the ones they could observe outside of the activity schedule. All the socio-health professionals who worked in the day center when the program took place participated in this focus group $(n=6)$. These professionals had direct knowledge of the activities that had taken place in the common rooms of the day center and sometimes they had collaborated with the 
educators in some practical tasks. This focus group was audio-recorded and transcribed for subsequent analysis.

\section{Results and discussion}

Out of the 24 persons considered eligible to participate in the program, finally 21 participated continuously. Three people who were considered eligible did not participate: a man and a woman who dropped out of the center shortly after starting the program, and a woman with dementia associated with Huntington's disease who only displayed sporadic interest in the program activities. The 21 participants in the program were 8 men and 13 women, age ranging between 67 and 93 years, whose distribution by age is shown in Table 1. All the participants had a diagnosis of mild $(n=13)$ or moderate $(n=8)$ dementia, which had been made between one and four years prior to their participation in the program. Their most recent scores in the Mini-Mental State

Table 1.
Distribution of the participants by age
\begin{tabular}{lll}
\hline Age & \\
\hline $60-69$ & 1 \\
$70-79$ & 4 \\
$80-89$ & 11 \\
90 or over & 3 \\
\hline
\end{tabular}

Examination (MMSE; (Folstein, Folstein, \& McHugh, 1975)), ranged between 12 and $27(M=19, S D=$ 4.6).

The number of sessions in which each user participated ranged between 5 and 22 $(M=10.4, S D=4.4)$. Five people participated in 14 or more sessions and three participated in $6(n=1)$ or in 5 sessions $(n=2)$ sessions. There were two reasons for these differences. Some people who were very interested in the activity participated in more sessions because they joined some sessions for which their participation had not been previously programmed. The people who participated in fewer sessions were temporarily out of the center while the sessions were taking place. The sessions were 
carried out in small groups of 2 to 11 participants, with a mean of 5.6 participants per $\operatorname{session}(S D=2.3)$.

In Figure 1 is shown an outline of the topics that were addressed with each one of the techniques employed (participant observation, assessment by educators, focus groups with people with dementia as participants, and focus group with the professional caretakers). These aspects are described in detail below.

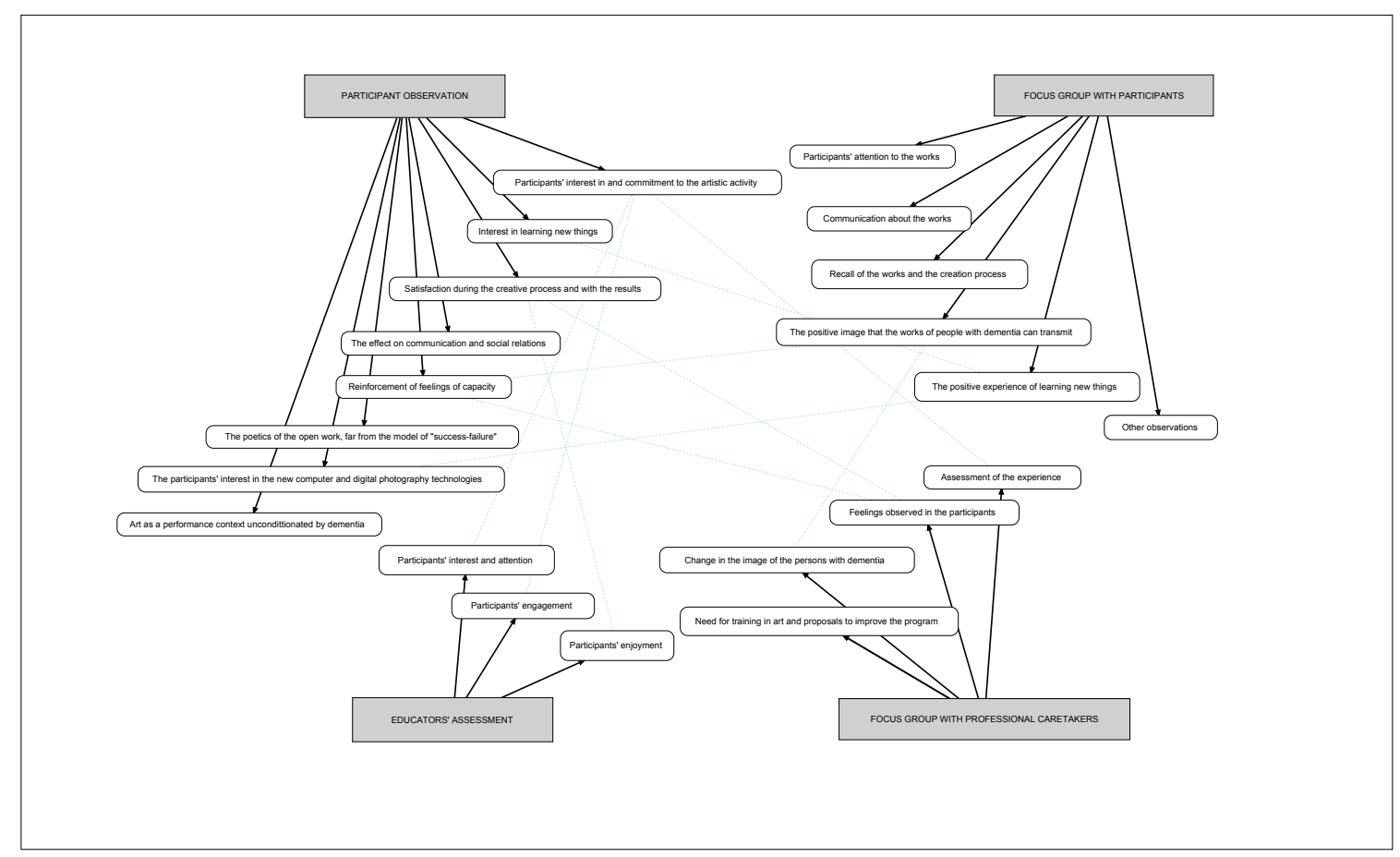

Figure 1. Topics that were addressed with each one of the techniques employed (participant observation, assessment by educators, focus groups with people with dementia as participants, and focus group with the professional caretakers)

\section{Participant observation}


The way the program developed allowed two of the authors (AMU and MHB) to join the group of educators and participants in the program naturally. Thus, they could make their observations while the activities of the diverse aspects described below were taking place.

\section{Participants' interest in and commitment to the artistic activity}

One of the first aspects observed was the participants' interest in and commitment to the activity. From the very start, the opportunity to look at the paintings was well accepted. After the projection of the paintings was over, the participants frequently looked at them again on the small laptop screens, either to comment on them in more detail or to continue animated discussions with the educators about diverse topics, individually or in groups of two or three people. In a specific case of a person who had a very high educational level, the effect was remarkable. This person normally wandered around the facilities constantly and this behavior decreased enormously during the projection of the paintings. He was highly motivated to look at the paintings, concentrating in silence in front of the computer. Although this reaction was quite remarkable, we could not attribute his motivation to contemplating the paintings to his high educational level and his high previous levels of cultural consumption (he played the violin, visited exhibitions, museums and concerts, wrote poetry, etc.). The observed level of motivation to contemplate the works was almost generalized. Sometimes people said they remembered the paintings of some of the more popular painters (i.e., Velázquez or Van Gogh), and they displayed reactions of satisfaction because of a "re-encounter", but sometimes they expressed pleasure about previously unknown authors, works, or styles,

with expressions like "I hadn't seen this before, but it's good" and comments and 
attitudes that denoted their interest in contemplating the works. In addition, their interest was not limited to the more popular figurative styles, which, however, always aroused their admiration because of the realism and accuracy of the portraits, landscapes, or still lifes. The selection of the works (see Table 4) included very diverse styles of the history of art and especially emphasized creations of the historical vanguards. No reactions of rejection were observed, rather a feeling of intrigue about other ways of representation ("What is this?" "Why do they paint it this way?"). Associating works like "Las Meninas" of Velázquez with cubist versions of this work painted by Picasso (which they saw through the on-line collection of the Picasso Museum of Barcelona http://www.bcn.cat/museupicasso/ca/colleccio/cataleg.html) generated a particularly interesting dynamic about different forms of representation. This dynamic not only continued during the participants' elaboration and personal work in the workshops in which they made different cyanotype versions of the Meninas (see the description of the workshops), but also emerged spontaneously throughout diverse sessions, even in the final focus groups. This dynamic contributed to generating a climate that promoted the creation of a personal work, free from the conventions of realism or of figurative painting.

Interest in learning new things: "I didn't think I could learn things like this at this point,"

Interest in learning new things was frequently observed, both in the first part of the workshops during the projection of the audiovisual material, and in the second part during the process of elaboration of the personal work. This interest was explicitly displayed by some participants with comments such as "I didn't think I could learn 
things like this at this point," with spontaneous affectionate expressions of gratitude to the monitors ("thanks for teaching us") and, sometimes, with affirmative responses to the question of whether they liked to learn about the paintings or about the cyanotype procedure. The way in which some participants described the contents of the program to others was remarkable, underlining the idea of learning to do something they had not done till then ("we learn to make paintings, we learn to make photos", etc.).

Satisfaction during the creative process and with the results

Another aspect observed was the general satisfaction expressed by the participants while performing the activity. They were concentrated, attentive, and engaged in the explanations and the processes, and some of the more expressive people frequently stated how much fun they had had. If they had not been able to finish for lack of time or they did not like the results, they would comment negatively about this. We observed that many participants enjoyed sharing the results obtained, their works, with their families. Some of them planned to give some of the paintings to their children, grandchildren, or great-grandchildren, and they were very pleased when their relatives liked the work, made remarks about it, framed it, and "commissioned new works." In general, the idea of exhibiting the works was received very positively, and they made interesting proposals about where to exhibit them, who might be interested in coming to see them, their diffusion, etc.

The effect on communication and social relations 
The development of the activities of the program was seen to promote communication processes with the participants, as it led to establishing spontaneous conversations with them about various topics, many of them related to these people's vital experience. References to family members were very frequent, they also mentioned experiences of their professional lives (where they used to work or their former job), their religious or political opinions, where they were born, their present or past hobbies, etc. These conversations allowed the educators and the investigators who performed the participant observation to very quickly get to know the participants personally, and they promoted the training and the establishment of affective relationships among them.

Reinforcement of feelings of capacity: "See how well it turned out"

From the first sessions, we observed that the activities reinforced the participants' feelings of capacity; when seeing the results obtained, they said things like, "I didn't think I could do something like this...", "See how well it turned out," etc. This observation was permanent, not only while performing and finishing the works, but also some days later, when they saw them again, and expressed positive surprise about their works. This reinforcement of feelings of capacity was observed with particular intensity when the personal works were included as part of the audiovisual material that was projected in the first part of the workshops. In these cases, the name and portrait of the author was added to the photograph. These projections were valued so positively by the participants that the educators included them several times as the central motif of various collective sessions.

The poetics of the open work, far from the model of "success-failure" 
Because of their diagnosis or cognitive rehabilitation, people with dementia are frequently faced with tasks that are done either well or badly, in which one is either successful or one fails. The creative experiences proposed in the program did not follow an assessment model of "good-bad", "success-failure". From the viewpoints closer to the poetics of open works of contemporary art (Eco, 1989), we emphasized that the appraisal of each work should be made from individual approaches that should take into account the process of accomplishment and the personal plastic elaboration of the work. Using as reference many artistic styles and movements allowed us to address the issue of different ways of plastic representation and the multiplicity of aspects of the aesthetic experience. We observed that the participants frequently asked the educators to appraise their works ("Like this?", "Is it alright?"). They responded from the above-mentioned approaches, which involved the possibility of many interpretations of the works and, therefore, far from the idea of "doing things right or wrong". The participants first reacted to this approach with surprise and later with pleasure and growing engagement, so that even those who at the beginning hardly dared paint or draw-because they said "they didn't do it right" — ended up creating expressive compositions that were quite remarkable.

The participants' interest in the new computer and digital photography technologies

The development of the program frequently required the use of laptops, digital cameras, printers, and, sometimes, an Internet connection. We observed that the participants were interested in learning how such technologies worked and the explanations they received were well accepted. Observers and educators both found the participants' interest in 
digital photography remarkable. Viewing the photographs on the camera or laptop screen, printing copies and even scanning photographs previously printed on paper, preparing positives and negatives of photographs or paintings were highly valued activities. One of the observers (MHB) had professional experience in photography and art. The participation of this photographer during the development of the sessions was important, not only to graphically document the processes and facilitate an image diary of the sessions. It also allowed us to obtain good portraits of the participants, thus providing them with a positive image of the portrayed person in which they recognized themselves and were recognized by others. These photographs of the participants, the processes, and the works were highly valued by the participants with dementia, so much so that they became a central element of one of the workshops (self-portrait workshop, see Table 4).

Art as a performance context unconditioned by dementia

Throughout the sessions of the program, we observed that the symptomatology of dementia was an aspect that did not condition — or only very slightly—-the participants' reactions, attitudes, or creative processes. Whereas their frequent sensorial (especially auditory) and/or mobility limitations could obviously condition their work in the workshops, there was no indication that the clinical syndrome of dementia with which these people were diagnosed was an obstacle to their participation. With some very occasional exceptions, neither the educators nor the observers could point out any aspect that might differentiate this group from any other group of adults who were participating in a similar activity. This program of artistic activities can be understood as a performance context unconditioned by the dementia presented by these people, and 
defining performance context as a setting and a series of associated tasks, roles, and concrete results. When observing these people concentrated on the contemplation of the works of diverse artists or participating in the elaboration of their personal creations, the only signs of these people's diagnoses were the external signs that distinguished the different roles within the organization (clothing, localizers or ID cards worn by the patients, etc.). This observation became a frequent subject for reflection among the educators and the observers.

Educators' assessment of the participants' interest and attention, engagement and enjoyment during the creative process

Of the 159 assessments of the participants' interest and attention during the workshop that the educators performed by completing the form shown in Table 5 (question 4), in 129 cases $(81 \%)$, the educators considered that the participants had displayed interest and attention continuously during the entire session; in 19 (12\%) cases, they thought that the participants had shown interest, but at intervals; they could reach no conclusions in 6 cases (4\%); and in 5 cases (3\%), they considered that the participants had not shown interest in performing the activity. Of the educators' 156 assessments of whether or not the participant had completed the work of the workshop (table 5, question 5), in 141 cases (90\%), they responded affirmatively; in 12 cases (8\%), they responded "partly"; and in 3 cases (2\%), they responded that the participants had not completed the activity. Of the 157 educators' appraisals of whether or not the participants had enjoyed the activity (table 5, question 6), in 105 cases (67\%), the answer was clearly yes, because either the participant had said so spontaneously, or they had observed their unambiguous pleasure; in 24 cases $(15 \%)$ they reached no 
conclusions about this issue; and in 4 cases $(3 \%)$, they considered that the participant had not enjoyed the activity because they had observed displeasure or disagreement.

\section{Focus groups with participants}

In the analysis of these focus groups, we thought beforehand that two topics would be especially relevant. The first was the participants' attention towards the works. The second referred to the participants' communication about the works, the results, and the creative process involved. During the analysis, several more topics were considered: the recall of the works and of the creative process, the capacity of the program to transmit a different image of people with dementia, and of the value of the learning processes. The general climate of the groups and the sense of humor predominant in them were also appraised, as well as whether the exchange of questions and answers in the groups was appropriate, and whether the participants correctly performed the task of giving titles to the works, and of making suggestions and proposals to continue the program.

Participants ' attention to the works: "at this point, I didn't know how to do it well, this was at the beginning"

The two investigators who reviewed the video recordings of the focus groups agreed that the participants paid much attention to their works, reviewing them frequently during the session. This attention was generally accompanied by positive verbal or nonverbal expressions. Participants occasionally expressed negative judgments about their own works ("I don't like the way this one turned out"), almost always mentioning comparative aspects ("at this point, I didn't know how to do it well, this was at the 
beginning"). In some cases in which the verbal expression of the participants was habitually very reduced, they spent the session looking at and reviewing their works, although when asked about their works by their classmates, or about some other issue, they would reply appropriately, so it could be deduced that they understood the general tone of the discussion in which they could participate if so required. Two participants with symptoms of intense decline did not intervene spontaneously in the conversation, but they smiled when looking at their works, especially when they were framed or when they received favorable comments about them by their classmates.

Communication about the works: "this picture of yours is extraordinary, because it's done with a brush"

As planned, it was usually easy to get the participants to talk about their works in the group setting. Sometimes they referred to the result obtained, appraising it ("I like it, it looks like art", "I like it because it is so original"). And sometimes, they expressed positive feelings verbally about the works ("I am excited about my picture") or the desire to share it ("How sad that my daughter is not here to see it!"). The aesthetic effect of framing the works with glass was also commented on ("the glass gives it a different look", "how nice it looks with the glass, the shininess of the glass"). They also judged their classmates' works, generally praising them ("this picture of yours is extraordinary, because it's done with a brush"), and such comments were received with smiles of pleasure even when the people had expressive difficulties.

Recall of the works and of the creation process: "I didn't remember that I had done this and now... what a surprise to see it now! Goodness gracious! (...) I can't believe I did it" 
Throughout the focus groups, participants frequently identified the works, compositions with natural plant elements, and still lifes they had seen in the workshops. They also remembered the processes followed ("this is from the glass...it's the reflection of the glass with the water that was there long enough"; "these are branches, they're represented with the sun and the water"). Sometimes, when reviewing the works carried out several weeks ago, some of the participants were surprised to see them ("I didn't remember that I had done this and now... what a surprise to see it now! Goodness gracious! (...) I can't believe I did it"). On these occasions, when asked whether they remembered the creation process, the participants could mention the steps of cyanotype more or less fluently ("we placed it outdoors, in the sunshine (...) then, we rinsed it in water"). Apparently, there was a better recall of the processes followed than of the concrete results obtained. This was also observed during their performance in the workshops. In one very descriptive case, a participant who was highly interested in the workshops although her participation was not programmed, after more than 7 sessions, when asked, replied that she had never done that, but she was capable of following the steps (making the composition, taking it outdoors to expose it to sunlight, and afterwards rinsing the paper, etc.) independently, with hardly any instructions, and verbalizing for others the sequence of steps to be followed. In the focus groups, one of the participants who said he could not remember having done any of the works, remembered the process followed to make them and recalled with no problem the aesthetic discussions he had had about the value of realism in painting. 
Spontaneously, various participants mentioned the surprise they felt when they realized they were capable of doing things like the works they framed. One of them emphatically entitled one of the paintings with the expression, "I made it!" In addition, they commented that it would be a good idea to present the works in public so that people would know about their skills and improve their opinion of the people who attended the center ("I hope that people will look at them"; "We should exhibit them so people will see what we're doing here, because, of course, nobody knows why we come"; "I think that when I come to the center...it's as if they thought I was...crazy, by losing my memory...(...). It took a great effort and tears to come to the center. I've read a lot and I thought they wanted to lock me up (...) Now they say, 'You see, mama?' I go around telling everyone that I'm very happy, (...) they're teaching us to paint”).

The positive experience of learning new things: "I have really enjoyed it, each day we learned something"

Various interventions focused on the participants' positive experience of learning new things ("it's always good to learn things in life", "it's always good to learn", "I didn't expect to learn", "I have really enjoyed it, each day we learned something", Look at all the things they've taught us". "Every day we learn things"). Sometimes, the experience of learning was related to educational lacks in infancy ("I always liked to paint, but of course, as we lived in a town with no resources, I would go by myself...my mother would say, 'What are you doing, child?' 'I'm writing, but it just came out of me, what I did came out of me (...) I really liked it, but in those times, there was absolutely nothing... that's the way it was"). 
Other observations about the participants' focus groups: "it's my own language that not everyone understands"

The climate of the focus groups with the participants in the program was very relaxed, with frequent episodes of laughter and humorous comments about the works, even about the participants' own cognitive difficulties (when the other participants asked the meaning of an apparently meaningless word, a participant said, laughing, "it's my own language that not everyone understands"). The task of naming the works was carried out with notable differences among the participants, but, in general, either alone or with the suggestions from the group, the task was performed without too many problems. Some of the titles were descriptive of the content of the works ("Bouquet", "Bouquet of leaves"), others were humorous ("Hands up!"), others reflected the feelings of the people for their creations ("I did it!"), or dedications ("For María Jesús"). Some of them were highly poetic ("Looking backwards"; "Rabindranath Tagore") and others were characteristic of the pictorial language used ("Collage", "Interpretation of the Meninas"). The exchange of questions and answers between the educators and the participants was appropriate and the participants made suggestions to improve diverse aspects of the workshops (frequency, appropriate number of people who could attend each one of the workshops, interesting techniques, or preferred supports) when so requested by the educators.

\section{Focus group with the professional caretakers}


There was a general agreement among the professionals who participated in this focus group that the experience was positive. This positive rating was justified by mentioning the creative nature of the activities and the innovation of this type of artistic activities in comparison to the daily routines of the people attended. Likewise, they mentioned that the user participation observed had been high and that it had even increased, and the individual work in the workshops was highly valued (Table 7, quote 1)

\section{Feelings observed in the participants}

Table 7.

Quotes from socio-health professionals

\begin{tabular}{|c|c|}
\hline Quote & \\
\hline 1 & $\begin{array}{l}\text { "...it was individual, because I think that, actually, all the workshops were } \\
\text { individual, the people did what they really wanted to do or said they wanted } \\
\text { to do, they felt comfortable, no user rejected anything, saying "I don't feel } \\
\text { like it, I don't want to"...at least that's what I think". }\end{array}$ \\
\hline 2 & "I think it even makes them feel more capable" \\
\hline 3 & "...because they make something that is beautiful, something important" \\
\hline 4 & $\begin{array}{l}\text { "I thought that A. was quite remarkable, especially at the beginning...she } \\
\text { showed me a facet I didn't know she possessed", }\end{array}$ \\
\hline 5 & $\begin{array}{l}\text {...and G. (...) because the first drawing she made of the ball and the } \\
\text { donkey and all that...it was very good...it surprised me, you know? And } \\
\text { later, talking with her, she told me "my daughter paints, and I love painting } \\
\text { too" and it was an unknown facet of hers...and I felt I could see... I don't } \\
\text { know what...in her...look at her! (...) and later painting and all, she really } \\
\text { surprised me", }\end{array}$ \\
\hline 6 & $\begin{array}{l}\text { "I also found E. noteworthy, being so meticulous,...and with his problem, } \\
\text { because he has trouble holding the brush...then so meticulous as he was } \\
\text { with the drawings and the techniques and so on, I really found it } \\
\text { remarkable...it's something that's not...and it was discovered" }\end{array}$ \\
\hline 7 & $\begin{array}{l}\text { "each one was a different world...it brought out something in all of them, } \\
\text { something we had not discovered" }\end{array}$ \\
\hline 8 & $\begin{array}{l}\text { "...the relatives should know what they are doing...there are many relatives } \\
\text { that do not know...they don't know anything about their relative's faculties" }\end{array}$ \\
\hline 9 & $\begin{array}{l}\text { "... some water colors or whatever and their relative will be realized...and } \\
\text { they should know that they can do it, perhaps they don't know because not } \\
\text { even we could have imagined it and we were with them every day...". }\end{array}$ \\
\hline 10 & $\begin{array}{l}\text { "and we had a lot of misgivings, a lot of questions, you observe, you make } \\
\text { mistakes, you think that the technique is a certain way but it is actually a } \\
\text { different way, you are not familiar with it, then I think that we should have } \\
\text { some prior training...." Aux } 2 \text {, }\end{array}$ \\
\hline 11 & $\begin{array}{l}\text { "...there were times when we interrupted you and said "why are you doing } \\
\text { it this way? and how do you do it?"...if we had had such prior training } \\
\text { before the workshop, we could have helped you more" }\end{array}$ \\
\hline
\end{tabular}

These professionals also mentioned the effect of the workshop on the participants' feelings of capacity as a positive element (Table 7, quote 2-3). They also mentioned the fact that the workshops allowed the people to express themselves (Table 7 , quote 4). They also agreed that the

participants were more relaxed during the development of the activities. 
Change in the image they had of the users

Another especially interesting topic noted by these professionals was that this activity had revealed some aspects that were till then unknown to them (Table 7, quote 5-7). In this regard, they also said that it would be interesting for the relatives to know this aspect of the patients' creativity (Table 7 quote 8-9).

Need for training in art and proposals to improve the program

The professionals who took care of the participants said that they had felt the lack of more training about the contents of the workshop (Table 7, quote 10-11). The proposals to improve the program made by these professionals coincided to a great extent with those made by the users (organization, sequence of sessions, time available for each session and each participant, ...).

\section{Conclusions}

The goal of this work was to present the results of a contemporary artistic educational program based on photographic cyanotype techniques carried out with people with early dementia. This is an exploratory qualitative study designed to appraise whether people with early dementia could participate in a program of this kind, determine their viewpoint of the program, and discover whether this kind of program could contribute to these people's experience. 
Various conclusions of the results obtained deserve more attention. The first refers to the fact that dementia was not an obstacle to participate in the program. The second refers to the contributions of the program to the experience of the people with early dementia who participated in it.

Art-related behaviors seem to imply, as mentioned, broad, diverse, and redundant brain areas, which justifies that neurodegenerative diseases can take a long time to affect creativity, artistic expressiveness, and aesthetic appreciation. (Zaidel, 2010). Our results are compatible with this hypothesis. In this sense, we emphasize that the people with dementia who took part in the program did not manifest any problem to participate and enjoy the arts, without any need to oversimplify and using the same approaches as those of an artistic educational program for adults without dementia. The skills of people with dementia are frequently underestimated, emphasizing their deficits and, consequently, they are faced with tasks of a low level of intellectual stimulation or sense of achievement. (Malone \& Camp, 2007; Perrin, 1997). These processes have been related to the concept of "extra-disability", understood as the discrepancy that occurs when a person's functional inability is higher than that justified by his or her actual damage (Chung, 2004). The results obtained in this work lead us to conclude that the effective limitation of access to artistic experiences for people with dementia may be the result of the stigma associated with dementia. People with dementia frequently face the double stigma of ageing and dementia (Benbow \& Reynolds, 2000; Katsuno, 2005). To this must be added the fear of being negatively stereotyped. Both aspects can negatively affect the subjective experience of people with dementia, their capacity to develop the cognitive skills that are still intact, their capacity to meet the demands of daily life, their quality of life, and their capacity to lead a meaningful life (Scholl \& 
Sabat, 2008). Stigma and stereotypes can also condition both the processes of diagnosis and the design of the support services for people with dementia (Vernooij-Dassen et al., 2005). Therefore, we think it is important to insist that, according to the results obtained in our work, in principle, there is no reason that should prevent making effective the acknowledged right of all persons, independently of their clinical condition of dementia, to participate in the cultural life of the community and to enjoy the arts, as stated in article 27 of the Universal Declaration of Human Rights.

From our results we also conclude that participation in the program could contribute various positive aspects to the experience of people with dementia. Mainly, there are three outstanding aspects: enjoyment, learning, and a better self-image. Taken conjointly, these three aspects are especially important with regard to the experience and well-being of people with early dementia. Other works have shown that older adults with dementia could increase their self-efficacy through their participation in learning opportunities (Richeson, Boyne, \& Brady, 2007; Simone \& Scuilli, 2006)and many professionals who work in the area of dementia consider that activities and being occupied are central to promoting the well-being of people with dementia (Brooker \& Woolley, 2007). In a similar vein, our results indicate the interest of the participants with dementia in the cultural and learning activities and their capacity to engage in them and to enjoy the experience.

The conditions described of the development and follow-up of the program allowed an approximation, not only to the processes and activities that were a part of it, but also to the general organization of caring for people with dementia. The experience ended by becoming a critical viewpoint from which to examine this organization of 
caretaking. In this sense, the need to change from a perspective of deficiencies, focused on losses - cognitive or otherwise - to a perspective of the potential of people with dementia, not only artistic or creative, but also human in general (sense of humor, capacity to enjoy, to establish affective relationships, to share experiences, etc.), was noteworthy. Some authors state that to study art and dementia is a model of the recognition of patients' strengths, and not only their weaknesses (Cummings et al., 2008). The development of our artistic educational program and the results obtained lead us to coincide with this viewpoint. Our experience reveals the need to support person-centered care, rather than pathology-centered care, to empathize with the subjective experiences of people with dementia, as well as the importance of intersubjectivity and relational aspects, issues that have already been mentioned by other authors (Nolan, Ryan, Enderby, \& Reid, 2002). From this perspective, we call attention to the need to critically review the intuitional routines of people with dementia insofar as they may be contributing to an oversimplified self-image that is harmful for their identity, their well-being, and their rights.

The exploratory nature of this study implies a series of limitations and also shows the need to continue certain relevant lines of research. Among the limitations are the size and composition of the sample, which did not allow a more detailed analysis of the results as a function of factors such as the participants' gender, or more detailed neurological diagnoses. Among the lines of research we consider appropriate to continue are the need to perform longitudinal studies of the effect of participation of people with dementia in artistic educational programs developed in community settings - not in special institutions - and to analyze the effect of participation in this 
kind of experiences on the relatives of people with dementia (spouses, children or grandchildren).

Tàpies, a famous 20th century Spanish vanguard artist, stated that art and culture are the conscience that man gives to himself and to the entire society (Tàpies, 1982). Vygotsky considered art, like language, a psychological tool aimed at mastering one's own psychic processes, with the capacity to globally modify the evolution and the structure of the psychic functions, as a means to influence oneself and others (Belver \& Ullán, 1996). In a similar vein, we think that the results of this work indicate that facilitating access to art and artistic education to people with dementia can contribute to enforce their rights and to improve the care systems provided for them.

\section{References}

Belver, M. H., \& Ullán, A. M. (1996). Estudio del comportamiento artístico desde la perspectiva psicosocial. El enfoque de Vigotsky. Arte, Individuo y Sociedad, 8, 51-63.

Benbow, S. M., \& Reynolds, D. (2000). Challenging the stigma of Alzheimer's disease. Hospital Medicine, 61, 174-177.

Brooker, D. J., \& Woolley, R. J. (2007). Enriching opportunities for people living with dementia: The development of a blueprint for a sustainable activity-based model. Aging \& Mental Health, 11(4), 371-383. doi: 10.1080/13607860600963687

Chung, J. C. C. (2004). Activity Participation and Well-Being of People With Dementia in Long-Term-Care Settings. Occupational Therapy Journal of Research, 24(1), 22-31.

Cohen, G. D., Perlstein, S., Chapline, J., Kelly, J., Firth, K. M., \& Simmens, S. (2006). The Impact of Professionally Conducted Cultural Programs on the Physical Health, Mental Health, and Social Functioning of Older Adults. The Gerontologist, 46(6), 726-734.

Cohen, G. D. (2009). New theories and research findings on the positive influence of music and art on health with ageing. Arts \& Health: An International Journal for Research, Policy and Practice, 1(1), 48-62.

Cummings, J., Miller, B. L., Christensen, D., \& Cherry, D. (2008). Creativity and dementia: emerging diagnostic Alzheimer's disease. CNS Spectrum, 13, 1-24.

Drago, V., Crucian, G. P., Foster, P. S., Cheong, J., Finney, G. R., Pisani, F., \& Heilman, K. A. (2006). Lewy body dementia and creativity: Case report. 
Neuropsychologia, $\quad$ 44(14), 3011-3015. doi: 10.1016/j.neuropsychologia.2006.05.030

Eco, U. (1989). The open work. Cambridge, Mass: Harvard University Press.

Fisher, B. J., \& Specht, D. K. (1999). Successful Aging And Creativity In Later Life. Journal of Aging Studies, 13(4), 457-472. doi: 10.1016/s0890-4065(99)00021-3

Folstein, M. F., Folstein, S. E., \& McHugh, P. R. (1975). "Mini-mental state" : A practical method for grading the cognitive state of patients for the clinician. Journal of Psychiatric Research, 12(3), 189-198. doi: 10.1016/00223956(75)90026-6

Fornazzari, L. R. (2005). Preserved painting creativity in an artist with Alzheimer's disease. European Journal of Neurology, 12(6), 419-424.

Halpern, A. R., Ly, J., Elkin-Frankston, S., \& O'Connor, M. G. (2008). "I Know What I Like": Stability of aesthetic preference in alzheimer's patients. Brain and Cognition, 66(1), 65-72. doi: 10.1016/j.bandc.2007.05.008

Katsuno, T. (2005). Dementia from the inside: how people with early-stage dementia evaluate their quality of life. Ageing and Society, 25, 197-214. doi: $10.1017 / \mathrm{s} 0144686 \mathrm{x} 0400279 \mathrm{x}$

Lopez-Pousa, S. (2009). El arte y la demencia. Alzheimer. Realidades e Investigación en demencia, 41(1), 2-3.

MacPherson, S., Bird, M., Anderson, K., Davis, T., \& Blair, A. (2009). An Art Gallery Access Programme for people with dementia: 'You do it for the moment'. Aging \& Mental Health, 13(5), 744-752. doi: 10.1080/13607860902918207

Malone, M. L., \& Camp, C. J. (2007). Montessori-Based Dementia Programming®: Providing tools for engagement. Dementia, 6(1), 150-157. doi: $10.1177 / 1471301207079099$

Mell, J. C., Howard, S. M., \& Miller, B. L. (2003). Art and the brain - The influence of frontotemporal dementia on an accomplished artist. Neurology, 60(10), 17071710.

Miller, B. L., Cummings, J., Mishkin, F., Boone, K., Prince, F., Ponton, M., \& Cotman, C. (1998). Emergence of artistic talent in frontotemporal dementia. Neurology, 51(4), 978-982.

Miller, B. L., Boone, K., Cummings, J. L., Read, S. L., \& Mishkin, F. (2000). Functional correlates of musical and visual ability in frontotemporal dementia. The British Journal of Psychiatry, 176(5), 458-463.

Nolan, M., Ryan, T., Enderby, P., \& Reid, D. (2002). Towards a More Inclusive Vision of Dementia Care Practice and Research. Dementia, 1(2), 193-211. doi: $10.1177 / 147130120200100206$

Paillard-Borg, S., Wang, H., Winblad, B., \& Fratiglioni, L. (2009). Pattern of participation in leisure activities among older people in relation to their health conditions and contextual factors: a survey in a Swedish urban area. Ageing \& Society, 29(05), 803-821. doi: doi:10.1017/S0144686X08008337

Perrin, T. (1997). Occupational need in severe dementia: a descriptive study. Journal of Advanced Nursing, 25(5), 934-941. doi: 10.1046/j.13652648.1997.1997025934.x

Richeson, N. E., Boyne, S., \& Brady, E. M. (2007). Education for older adults with early-stage dementia: Health promotion for the mind, body, and spirit. Educational Gerontology, 33(9), 723-736. doi: 10.1080/03601270701364438 
Scholl, J. M., \& Sabat, S. R. (2008). Stereotypes, stereotype threat and ageing: implications for the understanding and treatment of people with Alzheimer's disease. Ageing \& Society, 28, 103-130. doi: 10.1017/s0144686x07006241

Seifert, L. S., Drennan, B. M., \& Baker, M. K. (2001). Compositional Elements in the Art of Individuals with Alzheimer's-Type Dementia. Activities, Adaptation \& Aging, 25(3), 95-106.

Simone, P. M., \& Scuilli, M. (2006). Cognitive Benefits of Participation in Lifelong Learning Institutes. The LLI Review, 1(1), 44-51.

Tàpies, A. (1982). La realitat com a art. Barcelona: Laertes.

Ullán, A. M. (1995). Art and reality: the construction of meaning. Papers on Social Representations, 4, 111-124.

Vernooij-Dassen, M. J. F. J., Moniz-Cook, E. D., Woods, R. T., Lepeleire, J. D., Leuschner, A., Zanetti, O., . . . Iliffe, S. (2005). Factors affecting timely recognition and diagnosis of dementia across Europe: from awareness to stigma. International Journal of Geriatric Psychiatry, 20(4), 377-386. doi: $10.1002 /$ gps. 1302

Wikström, B. M. (2002). Social interaction associated with visual art discussions: A controlled intervention study. Aging \& Mental Health, 6(1), 82-87.

Zaidel, D. W. (2010). Art and brain: insights from neuropsychology, biology and evolution. Journal of Anatomy, 216(2), 177-183. doi: 10.1111/j.14697580.2009.01099.x

Ziesel, J. (2009). I'm Still Here: A Breakthrough Approach to Understanding Someone Living With Alzheimer's. New York: Penguin Books/Avery Press. 
Table 4.

Artists and works that make up each workshop

Workshop 1. The pleasure of looking. Las meninas of Velázquez

Diego Velázquez. The Family of Felipe IV, or Las Meninas. Circa 1656. Oil on canvas. Museo del Prado, Madrid, Spain.

Prince Baltasar Carlos on Horseback. Circa 1635. Oil on canvas. Museo del Prado, Madrid, Spain

Felipe IV on Horseback. Oil on canvas. 1628-1635. Museo del

Prado, Madrid, Spain

Maria de Austria. Circa 1652. Oil on canvas. Museo del Prado, Madrid, Spain

The Surrender of Breda or The Lances. Oil on canvas. 1635.

Museo del Prado, Madrid, Spain

The Fable of Arachne, or The Tapestry Weavers. Circa 1657. Oil

on canvas. Museo del Prado, Madrid, Spain

Workshop 2. Spanish school of still lifes and other ways of painting them

Diego Velázquez The Family of Felipe IV, or Las Meninas. Circa 1656. Oil on canvas. Museo del Prado, Madrid, Spain.

Zurbarán Still Life. Circa 1660. Oil on canvas. Museo del Prado, Madrid, Spain.

Luís Egidio Still Life. Circa 1760. Oil on canvas. Museo del Prado, Madrid, Meléndez Spain.

Juan Fernández "el Grapes. Second third of XVII century. Oil on canvas. Museo del

Labrador" Prado, Madrid, Spain

Jan van Kessel "el Still Life with flowers. First fourth of XVII century. Oil on copper

Viejo" plate. Museo del Prado, Madrid, Spain

Juan Arellano. Flower basket. Circa 1670. Oil on canvas. Museo del Prado, Madrid, Spain.

Paul Cézanne. $\quad$ La table de cuisine. Between 1888 and 1890. Oil on canvas. Musée d'Orsay, Paris, France.

Vincent van Gogh Sunflowers. 1888. Oil on canvas. National Gallery of Art, London,United Kingdom.

Pablo Picasso Still Life. 1901. Oil on canvas. Museo Picasso, Barcelona, Spain.

Juan Gris. Tres lámparas. 1911. Water color on paper. Museum of Art, Bern, Switzerland.

La ventana abierta. 1920. Meyer Collection, Zurich, Switzerland.

Giorgio Morandi Still Life (Natura morta). 1956. Oil on canvas. Museo Morandi, Bologne, Italy.

Still Life (Natura morta). 1957. Oil on canvas. Vatican

Pinacotheca. Rome. Italy.

Workshop 3. Ways of representing: Velázquez and Picasso. Cyanotype collage of Las Meninas. 
Diego Velázquez The Family of Felipe IV, or Las Meninas. Circa 1656. Oil on canvas. Museo del Prado, Madrid, Spain.

Pablo Picasso Las Meninas (conjunt).1957. Oil on canvas. Museo Picasso, Barcelona, Spain.

Las Meninas (conjunt sense Velázquez).1957. Oil on canvas.

Museo Picasso, Barcelona, Spain.

Las Meninas (infanta Margarita Maria MPB 70.436). 1957. Oil on canvas. Museo Picasso, Barcelona, Spain.

Las Meninas (infanta Margarita Maria MPB 70.459).1957. Oil on canvas. Museo Picasso, Barcelona, Spain.

Las Meninas (infanta Margarida Maria MPB 70.440). 1957. Oil on canvas. Museo Picasso, Barcelona, Spain.

Richard Hamilton Las meninas de Picasso. 1973. Definite imprint (artist's test AP 1/16). Etching, sugar-aquatint, soft varnish, dry point engraving, roulette, dry brush and burnisher. Artist's collection.

Manuel Valdés Queen Mariana (La Reina Mariana). 2001. Sculpture in bronze. Museo Guggenheim. Bilbao. Spain.

Equipo Crónica, La salita. 1970. Acrylic on canvas. The Museu Fundación Juan

Rafael Solbes y March. Palma de Mallorca. Spain.

Manuel Valdés

Workshop 4. Stones will talk about my landscape and my voice. Land-art. Cyanotype on stone.

Unknown

Andy Goldsworthy
Stonehenge

http://www.flickr.com/photos/samdrifter1500/5334835248/in/poolstonehenge

Image of the myth of Sisyphus

http://www.fotolog.com/aa_sangre_fria/53308932

Stone circle

http://www.flickr.com/photos/nature-art/2923138315/

Land art with rocks, branches and leaves

http://www.ecoedam.org/content/arte-efimero

White stones on the beach

http://www.flickr.com/photos/hiasl3/2754100569/

Colored stones on slate

http://arteletrasusamartin.blogspot.com/2010/11/el-land-art.html

Black hole with stones

http://abraelazuldelcielo.blogspot.com/2009/04/andy-goldsworthy-

land-art.html

Red and gray stones

http://abraelazuldelcielo.blogspot.com/2009/04/andy-goldsworthyland-art.html

Stones to crack

http://abraelazuldelcielo.blogspot.com/2009/04/andy-goldsworthyland-art.html

Unknown 3 images of

http://www.squidoo.com/land-art-explored- 


\begin{tabular}{ll}
\hline & $\begin{array}{l}\text { Stone portrait } \\
\text { http://pixdaus.com/index.php?pageno=9\&tag=+stones\&sort=tag }\end{array}$ \\
Circle \\
http://www.artatswissre.com/flash/index.cfm?ID=2E6B2DDB- \\
C767-66DA-913278F334FA1BE7\&artist=56 \\
Stones and tree \\
http://www.ecoedam.org/content/arte-efimero \\
Stone towers and arches \\
Juanjo Frechilla \\
Bil Dan & $\begin{array}{l}\text { Balanced rocks } \\
\text { http://www.nocturnar.com/forum/bellas-artes/263939-arte-del- }\end{array}$ \\
& equilibrio-de-bill-dan.html
\end{tabular}

Workshop 5. Painters who paint themselves. Self-portraits.

Diego Velázquez The Family of Felipe IV, or Las Meninas. Circa 1656. Oil on canvas. Museo del Prado, Madrid, Spain.

Self Portrait (detail of Las Meninas). Circa 1656. Oil on canvas. Museo del Prado, Madrid, Spain.

Botticelli Self Portrait. 1470. Tempera on wood. Pitti Palace, Florence, Italy. The Birth of Venus. 1484. Tempera on canvas. Uffizi Gallery, Florencia, Italy.

Leonardo da Vinci Self Portrait. 1513. Red ink. Biblioteca Real, Turin, Italy. Lady with an Ermine. 1488-1490. Czartorysky Museum, Cracovia, Poland.

El Greco Portrait of a Man. 1595-1600. Oil on canvas. Metropolitan Museum of Art, New York, USA.

El expolio. 1577-1579. Oil on canvas. Cathedral of Santa María, Toledo, Spain.

Francisco de Goya. Self Portrait. 1815. Oil on canvas from a fresco. Museo del Prado, Madrid, Spain.

The Clothed Maja. 1802-1805. Oil on canvas. Museo del Prado, Madrid, Spain.

Rubens Self Portrait. 1623. Oil on wood. Roya Collection, Windsor/ London, United Kingdom.

The Three Graces. 1636-1639. Oil on wood. Museo del Prado, Madrid, Spain.

Rembrandt. Self Portrait. 1655. Oil on wood. Kunsthistoriches Museum, Vienna, Austria.

Philosophe en méditation . 1632. Oil on wood. Musée du Louvre, Paris, France.

Delacroix Self Portrait. 1837. Oil on canvas. Musée du Louvre, Paris, France. July 28: Liberty Leading the People.1830. Oil on canvas. Musée du Louvre, Paris, France.

Paul Gauguin. $\quad$ Portrait de l'artiste au Christ jaune. 1893. Oil on canvas. Musée d'Orsay, Paris, France.

Arearea - Joyousness. 1892. Oil on canvas. Musée d'Orsay, Paris, France.

Vincent van Gogh Sunflowers. 1888. Oil on canvas. National Gallery of Art, London, 


\begin{tabular}{ll}
\hline & United Kingdom. \\
& Self Portrait. 1889. Oil on canvas, Musée d'Orsay, Paris, France. \\
Paul Cézanne & Self Portrait. 1875. Oil on canvas. Private collection. \\
& Still Life. 1895-1900. Oil on canvas. Musée d'Orsay, Paris, France. \\
Renoir & Self Portrait. 1910. Oil on canvas. Durand-Ruel Collection, New \\
& York, USA. \\
& Two Sisters (On the Terrace). 1881. Oil on canvas. Institute of Art, \\
& Chicago, USA. \\
& Self Portrait. 1919. Oil on canvas. Museo de Arte Contemporáneo \\
Modigliani & de la Universidad de Sao Paulo, Brasil. \\
& Reclining Nude. 1917. Museum of Modern Art, New York, USA. \\
& Autorretrato con mono. 1938. Oil on wood. Collection of Albright- \\
& Knox Art Gallery, New York, USA. \\
& Las dos Fridas. 1939. Oil on canvas. Museo de Arte Moderno, \\
& México. \\
& Autorretrato. 1907. Oil on canvas. Narodni Gallery, Prague, Czech \\
& Republic. \\
& Guernica. 1937. Oil on canvas. Museo Nacional Centro de Arte \\
& Reina Sofia, Madrid, Spain \\
\hline
\end{tabular}

